\title{
Flame Heights of Fuel Arrays with Combustion in Depth
}

\author{
GUNNAR HESKESTAD \\ Factory Mutual Research Corporation \\ 1151 Boston-Providence Turnpike \\ Norwood, MA 02062 USA
}

\begin{abstract}
Three series of test fires conducted by Factory Mutual Research Corporation in the past, involving deep storages, have been analyzed for flame height, using both video records and temperature measurements on the plume centerline. The test series included $4.5 \mathrm{~m}$ high palletized storage of different commodities ( 13 tests), 3 to $6 \mathrm{~m}$ high rack storage of two different commodities (11 tests), and wood pallets stacked 0.3 to $3.4 \mathrm{~m}$ high (13 tests), all with ignition at the bottom. When flames extended above the storage, their heights were well represented by a correlation for pool fires, referencing the mean flame height to the base of the combustion region (bottom of storage in the present case) and representing the fire diameter as if the fire spreads as a cylindrical volume in the storage (volume spread). An exception was rack storage of a relatively thin, combustible layer (corrugated) over an inert, steel box, comprising a pallet load, for which the fire diameter had to be based on surface spread rather than volume spread. The virtual origin (from which the plume above the flames appears to originate), determined for some of the test fires, appeared predictable from flame height as in pool fires, but requires knowledge of the convective fraction of the total heat release rate, which may not be a constant fraction of the total heat release rate during fire development in the storage.
\end{abstract}

KEYWORDS: Flame Height, Virtual Origin, Storage

\section{INTRODUCTION}

Knowledge of fire plume dynamics is based mainly on experiments with pool fires. These include fires in liquid fuels contained in circular or noncircular vessels. They also include other fires generated above horizontal surfaces, such as gas fires above horizontal discharge openings or porous discharge surfaces, and monolithic or granular solid fuels burning on horizontal surfaces. Fire plume characteristics for which good engineering knowledge has been developed for such fires include flame heights as well as temperatures, velocities, and air entrainment in both the reacting plume below the flame tip and the nonreacting plume above the flame tip [1]. For lack 
of experimental information on other types of fires, such as deep storage fires, it might be assumed that the top of the combustible storage is equivalent to the surface of a pool for the purpose of engineering calculations, but it is difficult to justify such an assumption.

A perceived link between pool fires and deep storage fires is the flame height. For example, the plumes above the flame tip of the two types of fires should be similar, as should the mass flow rate of gases (mostly from entrained air) at the flame tip. Consequently, if the flame height can be predicted for deep storage fires, other fire characteristics should follow. These concepts, together with a frequent need to calculate plumes above deep storage fires, provided the incentives for analyzing three selected series of fire tests, conducted at Factory Mutual Research Corporation (FMRC) in the past, for flame height. These series include the Stored Plastics test program [2], which incorporated freeburn tests of many different plastic commodities in approximately $4.5 \mathrm{~m}$ high palletized storage. The others are the Wood Pallet program [3], involving freeburn tests of wood pallets stacked 1 to 45 pallets high $(0.14$ to $6.4 \mathrm{~m})$, and freeburn Rack Storage fires 2 to 4 tiers high ( 3 to $6 \mathrm{~m}$ ) of FMRC Class II Commodity and FMRC Plastic Commodity $[4,5]$. Much of the data needed in this analysis was recovered from video tapes and laboratory notes filed in the FMRC library.

\section{POOL FIRE BASELINE}

The mean flame height marks the level where combustion reactions are essentially complete and the inert plume can be considered to begin. Heskestad [6] derived a correlation model for flame height of pool fires assuming infinitely fast reaction kinetics. The model assumed: 1) that the flame would extend to a height where the total flux of entrained air at lower levels is sufficient to complete the combustion reactions (recognizing that much of the air entrained below the flame tip never takes part in the combustion reactions);2) that the air demand from the surroundings is proportional to the stoichiometric requirements of the pyrolysis gases; and 3) that the total entrainment rate obeys the relationship established by Ricou and Spalding [7] for the local entrainment rate in jets of different density than the surroundings. The following relationship for dimensionless flame height was derived $[6,8]$ :

$\mathrm{L} / \mathrm{D}=\mathrm{fn}(\mathrm{N} / \alpha)$

where $\mathrm{L}$ is the mean flame height above the pool surface, $\mathrm{D}$ is the pool diameter, $\alpha$ is the convective fraction of the heat release rate, and:

$\mathrm{N}=\left[\mathrm{c}_{\mathrm{p}} \mathrm{T}_{\infty} /\left(\mathrm{g} \rho_{\infty}{ }^{2}\left(\mathrm{H}_{\mathrm{c}} / \mathrm{r}\right)^{3}\right)\right] \mathrm{Q}^{2} / \mathrm{D}^{5}$

In Eq. (2), $Q$ is the heat release rate; $H_{c}$ is the heat of combustion per unit mass; $r$ is the stoichiometric mass ratio, air to combustible, $c_{p}$ is the specific heat of air at constant pressure; $\mathrm{T}_{\infty}$ and $\rho_{\infty}$ are the ambient temperature and density, respectively, and $\mathrm{g}$ is the acceleration of gravity.

Eq. (1), with $\alpha$ deleted since it is generally not known and is perceived to not vary appreciably, has been found to correlate experimental data on mean flame heights of pool fires very well over 
a wide range of fire sizes and combustibles $[6,8,9]$. The following correlation equation represents the entire range of fires from values $\mathrm{N}$ near $10^{-6}$ to $10^{5}$ :

$\mathrm{L} / \mathrm{D}=-1.02+15.6 \mathrm{~N}^{1 / 5}$

The high limit on $\mathrm{N}$ corresponds to the beginning of effects of high discharge momentum at the source. The low limit $\left(\mathrm{N}=1.20\left[10^{-6}\right]\right.$ ) corresponds to $\mathrm{L} / \mathrm{D}=0$, near which experiments indicate that the flame cover will break up into flaming and nonflaming areas [9].

A convenient engineering form of Eq. (3) has been derived [1], being a good approximation for common fuels and normal atmospheric conditions:

$\mathrm{L} / \mathrm{D}=-1.02+0.235 \mathrm{Q}^{2 / 5} / \mathrm{D}$

( $\mathrm{L}$ and $\mathrm{D}$ in $\mathrm{m} ; \mathrm{Q}$ in $\mathrm{kW}$ )

The virtual origin of a fire plume is a point source from which the plume above the flames appears to originate. The virtual origin enters the equations for temperature rise and velocity in the inert plume, as well as the mass flow rate of entrained air above the flames [10]. An explicit expression for $\mathrm{z}_{\mathrm{o}}$, the elevation of the virtual origin above the pool surface (below the surface if negative), has been derived and calibrated against experimental data [10] on $z_{o}$ from temperatures on the plume centerline. This expression assumes normal atmospheric conditions and a constant convective fraction of the total heat release rate $(\alpha=0.7)$ :

$\mathrm{z}_{\mathrm{o}} / \mathrm{D}=-1.02+0.083 \mathrm{Q}^{2 / 5} / \mathrm{D}$

$\left(\mathrm{z}_{\mathrm{o}}\right.$ and $\mathrm{D}$ in $\mathrm{m}$; $\mathrm{Q}$ in $\left.\mathrm{kW}\right)$

However, if a constant fraction of convective heat release cannot be assumed, but the flame height is predictable, the original derivation [10] includes the following expression from which $\mathrm{z}_{\mathrm{o}}$ can be calculated:

$\mathrm{L}-\mathrm{z}_{\mathrm{o}}=0.175 \mathrm{Q}_{\mathrm{c}}^{2 / 5}$

( $\mathrm{L}$ and $\mathrm{z}_{\mathrm{o}}$ in $\mathrm{m} ; \mathrm{Q}_{\mathrm{c}}$ in $\mathrm{kW}$ )

Here, $Q_{c}$ is usually known as the convective heat release rate $(\alpha Q)$, the heat left over and carried by the plume above the flame tip following heat transfer to the fuel surface to maintain the combustion and heat loss by radiation to the surroundings from the flaming region. (The previous form [10] of Eq. (6) employed the less accurately calculated coefficient 0.15 rather than 0.175 .)

Locations of virtual origins are often established from data of temperature rise on the plume axis above the flame tip, using the temperature rise equation valid for this region [1]:

$\Delta \mathrm{T}_{\mathrm{o}}=\mathrm{C}_{\mathrm{T}} \mathrm{Q}_{\mathrm{c}}^{2 / 3}\left(\mathrm{z}-\mathrm{z}_{\mathrm{o}}\right)^{-5 / 3}$

Here, $\mathrm{C}_{\mathrm{T}}$ is a dimensional constant and $\mathrm{z}$ is the height above the pool surface. A plot of $\Delta \mathrm{T}_{\mathrm{o}}^{-3 / 5}$ versus $\mathrm{z}$ produces a straight line which intercepts the $\mathrm{z}$-axis at $\mathrm{z}_{\mathrm{o}}$. 


\section{TEST CONDITIONS AND PROCEDURES}

\section{Stored Plastics Program}

The Stored Plastics test program [2] consisted of three types of tests, but only those known as "small-scale" are useful for the current purpose. These were freeburn tests of palletized storage involving a number of plastic products, often in corrugated cartons, loaded on wood pallets. The tests were conducted at the $18.3 \mathrm{~m}$ high site of FMRC's fire test building in West Glocester, R.I. The floor area of this building is $61 \mathrm{~m} \mathrm{x} 76 \mathrm{~m}$.

Referring to Fig. 1, a test array consisted of four stacks, each containing three pallet loads of material. The stacks were 4.1 to $4.9 \mathrm{~m}$ high, butted together in one direction and separated in the other by $0.15 \mathrm{~m}$, covering a floor area of $2.44 \mathrm{~m}$ by $2.59 \mathrm{~m}$. The fuel array was placed on a 0.3 $\mathrm{m}$ high weighing platform resting on the floor to measure mass loss rates. Ignition was by a 0.08 $\mathrm{m}$ diameter, $0.15 \mathrm{~m}$ long cellucotton roll soaked in $240 \mathrm{~m} \ell$ gasoline, placed in a plastic bag and located in the center of the $0.15 \mathrm{~m}$ space at the top of the first pallet. A portable cage surrounded the fuel array to keep the stacks upright as long as possible and to retain commodities on the platform should the pile collapse.

Table 1 includes a list of tests from the Stored Plastics (SP) program for which appropriate data are available (flame height and burning rate). For each test array the percent makeup of the combustible is indicated, as well as the height of the array.

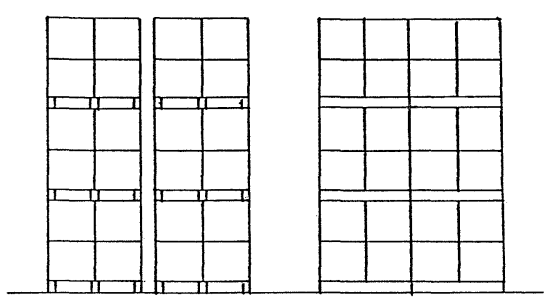

FIGURE 1. Two views of palletized storage, 4.1 to $4.9 \mathrm{~m}$ high, of Stored Plastic test program [2]. Ignition was at the bottom of the vertical flue, $0.15 \mathrm{~m}$ wide.
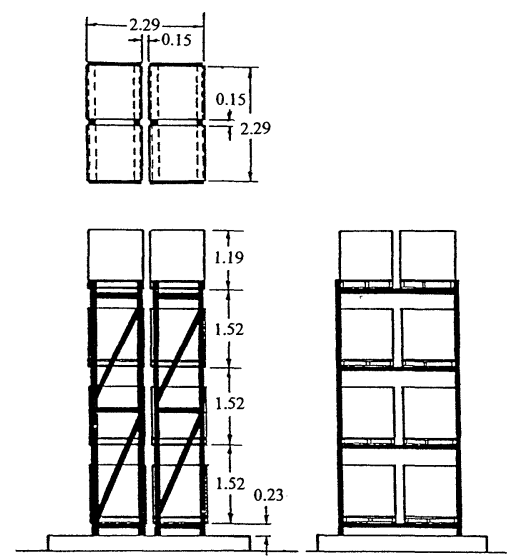

FIGURE 2. Four-tier high storage of Rack Storage tests $[4,5]$. Two- and three-tier storages were also tested. Dimensions are in $\mathrm{m}$. 
TABLE 1. Description of combustible arrays.

( $\mathrm{PS}=$ polystyrene $; \mathrm{PE}=$ polyethylene $; \mathrm{PVC}=$ polyvinylchloride $; \mathrm{PP}=$ polypropylene;

$\mathrm{PU}=$ polyurethane $;$ comp.$=$ compartmented $;$ cart. $=$ corrugated cartons)

\begin{tabular}{|c|c|c|c|c|c|}
\hline \multirow[b]{2}{*}{ Test } & \multirow[b]{2}{*}{ Combustibles } & \multicolumn{3}{|c|}{ Percent Content } & Array \\
\hline & & Pl. & Cart. & Wood & Height (m) \\
\hline
\end{tabular}

\section{Stored Plastics (SP)}

$\begin{array}{ll}\text { SP-4 } & \text { Jars in comp. cart. } \\ \text { SP-13 } & \text { Meat trays, foamed, wrapped in plastic. } \\ \text { SP-23 } & \text { Meat trays, foamed, wrapped in paper. } \\ \text { SP-30A } & \text { Toy parts in cart. } \\ \text { SP-35 } & \text { Insulation board, foamed. } \\ \text { SP-44 } & \text { Tubs, nested in cart. } \\ \text { SP-15 } & \text { Bottles in comp. cart. } \\ \text { SP-22 } & \text { Trash barrels in cart. } \\ \text { SP-43 } & \text { Bottles in cart. } \\ \text { SP-6 } & \text { Bottles in comp. cart. } \\ \text { SP-19 } & \text { Tubs in comp. cart. } \\ \text { SP-34 } & \text { Insulation board, rigid foam. } \\ \text { SP-41 } & \text { Cartons, comp., empty. }\end{array}$

$\begin{array}{lrrr}62(\mathrm{PS}) & 2 & 17 & 4.11 \\ 50(\mathrm{PS}) & 0 & 50 & 4.88 \\ 49(\mathrm{PS}) & 4 & 47 & 4.90 \\ 69(\mathrm{PS}) & 7 & 24 & 4.48 \\ 79(\mathrm{PS}) & 7 & 14 & 4.17 \\ 79(\mathrm{PS}) & 7 & 14 & 4.17 \\ 41(\mathrm{PE}) & 31 & 28 & 4.20 \\ 50(\mathrm{PE}) & 22 & 28 & 4.51 \\ 28(\mathrm{PE}) & 28 & 44 & 4.41 \\ 37(\mathrm{PVC}) & 36 & 27 & 4.63 \\ 35(\mathrm{PP}) & 30 & 35 & 4.26 \\ 45(\mathrm{PU}) & 19 & 36 & 4.57 \\ 0 & 50 & 50 & 4.51\end{array}$

\section{Rack Storage (RS)}

\begin{tabular}{lc}
\hline RS-1 & Cart., double triwall, metal liner. \\
RS-2 & $"$ \\
RS-3 & $"$ \\
RS-4 & $"$ \\
RS-5 & $"$ \\
RS-6 & "
\end{tabular}

RS-6

RS-7 PS cups in comp. cart.

RS-8

RS-9

RS-10

RS-11

$\begin{array}{lll}0 & 62 & 38 \\ 0 & 62 & 38 \\ 0 & 62 & 38 \\ 0 & 62 & 38 \\ 0 & 62 & 38 \\ 0 & 62 & 38 \\ 39(\mathrm{PS}) & 29 & 32 \\ 39(\mathrm{PS}) & 29 & 32 \\ 39(\mathrm{PS}) & 29 & 32 \\ 39(\mathrm{PS}) & 29 & 32 \\ 39(\mathrm{PS}) & 29 & 32\end{array}$

2.95 (2 tiers)
2.95 (2 tiers)
2.95 (2 tiers)
4.47 (3 tiers)
4.47 (3 tiers)
5.99 (4 tiers)
2.90 (2 tiers)
2.90 (2 tiers)
2.90 (2 tiers)
4.42 ( 3 tiers)
5.94 (4 tiers)

\section{Wood Pallets (WP)}

$\begin{array}{lc}\text { WP-1 } & \text { Wood Pallet. } \\ \text { VP-2 } & " \\ \text { WP-3 } & " \\ \text { WP-4 } & " \\ \text { VP-5 } & " \\ \text { WP-6 } & " \\ \text { WP-7 } & " \\ \text { WP-8 } & " \\ \text { WP-9 } & " \\ \text { WP-10 } & " \\ \text { WP-11 } & " \\ \text { WP-12 } & " \\ \text { WP-13 } & \end{array}$

$\begin{array}{llll}0 & 0 & 100 & 1.85 \text { (13 pall.) } \\ 0 & 0 & 100 & 1.28 \text { (9 pall.) } \\ 0 & 0 & 100 & 0.70 \text { (5 pall.) } \\ 0 & 0 & 100 & 0.43 \text { (3 pall.) } \\ 0 & 0 & 100 & 0.28 \text { (2 pall.) } \\ 0 & 0 & 100 & 0.43 \text { (3 pall.) } \\ 0 & 0 & 100 & 0.70 \text { (5 pall.) } \\ 0 & 0 & 100 & 2.56 \text { (18 pall.) } \\ 0 & 0 & 100 & 1.55 \text { (11 pall.) } \\ 0 & 0 & 100 & 1.85 \text { (13 pall.) } \\ 0 & 0 & 100 & 2.28 \text { (16 pall.) } \\ 0 & 0 & 100 & 3.41 \text { (24 pall.) } \\ 0 & 0 & 100 & 2.56 \text { (18 pall.) }\end{array}$


Among the instruments were thermocouples located 3.05, 6.10, and $9.14 \mathrm{~m}$ down from the ceiling, for which detailed temperature records were available [11]. Previous work indicates that the mean flame height of pool fires for normal atmospheric conditions corresponds to a temperature rise on the plume axis of $500 \mathrm{~K}$ [1]. Accordingly, the flame height was deemed to coincide with a specific thermocouple level whenever its thermocouple first indicated a temperature rise of $500 \mathrm{~K}$ above ambient. Only a few visual observations of flame height were made.

Heat release rates associated with specific flame heights were calculated from the associated mass loss rates, employing a heat of combustion. For each test, the heat of combustion was weighted according to mass fraction of plastic and corrugated in the array, assuming very little wood was consumed during the observation period. Heats of combustion (actual) were taken from Tewarson [12], including $13.2 \mathrm{~kJ} / \mathrm{g}$ for corrugated and the following values for plastics: $39.2 \mathrm{~kJ} / \mathrm{g}$ for polystyrene (PS); $38.4 \mathrm{~kJ} / \mathrm{g}$ for polyethylene (PE); $38.6 \mathrm{~kJ} / \mathrm{g}$ for polypropylene (PP); and 18.0 $\mathrm{kJ} / \mathrm{g}$ for polyurethane (PU).

Test SP-6 is listed as polyvinylchloride (PVC) in Table I, as in the report [2], which is probably erroneous. Properties listed from laboratory tests for this plastic [2] are not consistent with PVC, but quite consistent with PE. Accordingly, the heat of combustion for PE was adopted for SP-6.

\section{Rack Storage Freeburns}

Eleven freeburns were conducted to investigate the growth and plume characteristics of rack storage fires, using two different commodities in two, three and four tiers of storage [4,5]. The tests were conducted at the $18.3 \mathrm{~m}$ high site of FMRC's fire test building at West Glocester, R.I.

One of the two commodities was FMRC Standard Class II, which consists of $1.07 \mathrm{~m} \mathrm{x} 1.07 \mathrm{~m}$ $\mathrm{x} 1.07 \mathrm{~m}$ double triwall corrugated carton with a sheet metal liner. The double carton weighed $38.1 \mathrm{~kg}$ and the liner $23.1 \mathrm{~kg}$. The other was FMRC Standard Plastic commodity, comprised of polystyrene cups in compartmented corrugated cartons, eight cartons to the pallet load. The empty carton with cardboard dividers weighed $2.73 \mathrm{~kg}$ and the polystyrene cups $3.66 \mathrm{~kg}$.

Figure 2 illustrates a four-tier high storage with dimensions. The storage was weighed on a load platform. The ignition source consisted of four $0.08 \mathrm{~m}$ diameter, $0.08 \mathrm{~m}$ long cellucotton rolls, each soaked in $120 \mathrm{~m} \ell$ gasoline and wrapped in a plastic bag, which were placed near the bottom of the central flue space of the array.

The conditions for the eleven tests of the Rack Storage (RS) are included in Table 1. Tests RS-1 to RS-6 involved FMRC Class II commodity; Tests RS-7 to RS-11 involved FMRC Standard Plastic commodity.

The instrumentation included five instrument levels above the fuel array, each carrying a number of thermocouples and velocity probes to map plume profiles in orthogonal directions across the plume. The instrument racks were mounted at five elevations above the floor: $7.32 \mathrm{~m}, 8.84 \mathrm{~m}$, 
$10.97 \mathrm{~m}, 13.11 \mathrm{~m}$, and $15.24 \mathrm{~m}$. The load platform of the fuel array either rested on the floor or on a platform $3.35 \mathrm{~m}$ above the floor.

Heat release rates used here in conjunction with observed flame heights were calculated from mass loss rates, employing heats of combustion weighted on the relative fractions of plastic (if any) and corrugated, again discounting any contribution of the wood pallets during the observation period, resulting in $13.2 \mathrm{~kJ} / \mathrm{g}$ for Class II commodity and $21.1 \mathrm{~kJ} / \mathrm{g}$ for Standard Plastic commodity.

It was possible to determine only eight flame heights from the thermocouple indications in this case, using the same method as in the preceding program, i.e., considering a first temperature rise (smoothed temperatures using a 10-second running average) of $500 \mathrm{~K}$ at an instrument level to be equivalent to a mean flame reach to that level. Most flame heights were determined visually from the video tapes, seeking the times that the flames exceeded an easily observable level about fifty percent of the time. "Easily observable levels" were usually one of the instrument racks, but they also included the top of the storage, the earliest observation made in any fire test. With the time of occurrence of a given flame height, the associated mass burning rate and heat release rate could be established.

The reports on these tests $[4,5]$ provided data on convective heat release rates and for calculating virtual origins, which allowed us to examine the validity of Eq. (6) for deep storage fires.

\section{Wood Pallet Burns}

A large number of freeburn tests of stacks of wood pallets were conducted by Factory Mutual (Engineering Association) during the 1960's. Tests on single stacks ranging in height from 1 to 45 pallets $(0.14-6.4 \mathrm{~m})$ were examined for the purpose of this study, reported by Krasner [3] and additionally documented in laboratory notebooks filed with the FMRC library. All the tests for which mass loss rates and data for flame height were available have been used in this study, which include 13 tests with stack heights ranging in height from 2 to 24 pallets, or $0.3-3.4 \mathrm{~m}$. These tests are listed under Wood Pallets in Table 1, renumbered WP-1 through WP-13 for the purpose of this report.

The tests were conducted in test buildings in both Norwood, MA and West Glocester, R.I. The pallet stacks rested on a load cell platform which provided data for weight loss rate, from which heat release rate was calculated using a heat of combustion of $12.0 \mathrm{~kJ} / \mathrm{g}$ [12]. Two ignitors were used, each centered under one half of the lowest pallet.

Thermocouples were arranged along a vertical steel strap, placing the thermocouple beads on the vertical geometric centerline of the stack at intervals of usually $0.61 \mathrm{~m}$. For each test, certain of these rather closely spaced thermocouples were selected for attention. Each thermocouple temperature was followed as a function of time and the time established when the first temperature indication exceeded $500 \mathrm{~K}$ above ambient, considered simultaneous with the mean flame height reaching the elevation of the thermocouple. The weight loss record for that time indicated the associated mass loss rate and, by calculation, the associated heat release rate. 


\section{FLAME HEIGHTS}

\section{Stored Plastics}

The Stored Plastics fires were the first to be examined. There was a general expectation that the flame heights would behave in a manner similar to the pool fire relationship in Eq. (4), but the selection of a reference level for the flame height and fire diameter, D, appeared problematic.

As reference level, the base of the fire appeared a possibility. The original correlation form for pool fires, Eq. (3), was derived on considerations of air entrainment requirements from the surroundings to complete the combustion reactions. Air entrainment starts at the base of the fire, supporting the concept of the fire base as a reference level for flame height. However, air entrainment rates into flames within flue spaces deep in a storage could be much different from air entrainment rates into flames of pool fires, which suggested that the reference level, if Eq. (4) has any relevance at all to deep storages, could be a level other than the fire base and could be expected to depend on the detailed geometry of the storage. Nevertheless, it seemed natural to first try the base of the fire as a reference level, i.e., to represent flame height as the flame reach above the base of the fire.

With respect to the fire diameter, $\mathrm{D}$, the following concept served as a foundation. The storage fire was visualized, soon after ignition, to spread quickly to the top and then relatively slowly in the radial direction from the vertical ignition flue. The combustion region can then be viewed as an expanding circular cylinder, involving ever more combustible material until the entire fuel array is involved. The heat release rate per unit plan area involved in fire, Q", is assumed to be constant, taken as the maximum heat release rate of the array (occurring before decay sets in) divided by the plan area of the array. If the instantaneous heat release rate during fire growth is $\mathrm{Q}$, the associated fire diameter is:

$\mathrm{D}=\left[4 \mathrm{Q} /\left(\pi \mathrm{Q}^{\prime \prime}\right)\right]^{1 / 2}$

Most of the flame heights were determined using the plume temperature criterion ( $500 \mathrm{~K}$ above ambient). However, a few visual observations were made by the original test team (from file in FMRC library).

The Stored Plastics results of flame height are plotted in Fig. 3. The dashed line is a reference curve, representing the pool fire correlation in Eq. (4). We were surprised indeed to discover such a good correspondence between the storage fire and the pool fire flames. Note that the visual observations (solid symbols) are in good agreement with the other data, based on plume temperature.

These tests involved many variations in combustible material, which instilled a great deal of confidence in the generality of the agreement with pool fire results in Fig. 3. However, the matter of geometry of the storage, especially the flue spaces and depth of storage which remained essentially invariant in the Plastics Storage fires, called for attention. This led to a search and the identification of the additional data available from the Rack Storage and Wood Pallet fires. 


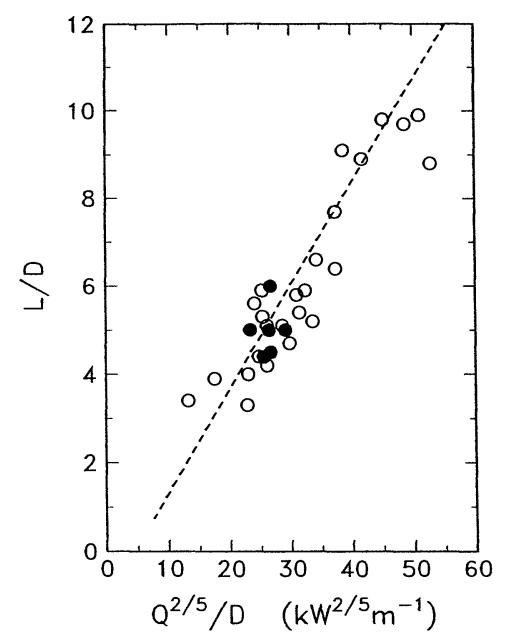

FIGURE 3. Stored Plastic tests: Dimensionless flame heights above base of fire. Open symbols are based on plume centerline temperatures; solid symbols are based on visual observations. The dashed line is the pool fire correlation in Eq. (4).

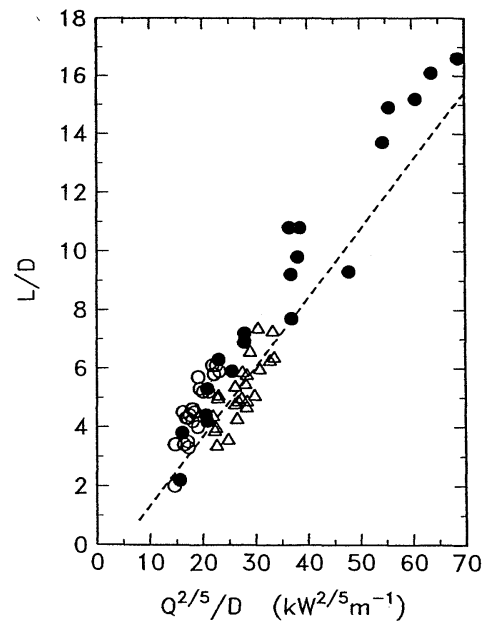

FIGURE 4. Rack Storage tests: Dimensionless flame heights above base of fire. Open circles represent FMRC Standard Class II commodity; open triangles represent FMRC Standard Plastic commodity; the dashed line is the pool fire correlation in Eq. (4). The solid circles are the opencircle results replotted based on $D_{S}$, rather than $D$.

\section{Rack Storage}

The Rack Storage flame height results were mostly visual, with a few based on the plume temperature criterion.

The results of $L / D$ versus $Q^{2 / 5} / \mathrm{D}$ are plotted in Fig. 4 as open symbols, together with a plot of the pool fire reference, Eq. (4). It is seen that the flame heights from tests with FMRC Standard Plastic commodity agree well with the pool fire reference, but that the results from tests with FMRC Standard Class II commodity tend to plot high.

The somewhat nonconforming results from the Class II fires were at first puzzling, until it was realized that this commodity is quite special in that the combustible material exists as a relatively thin layer (corrugated) over an inert box. The definition of fire diameter introduced in conjunction with the Plastics Storage, Eq. (8), would not seem to be representative for Class II commodity.

Instead of radial, cylindrical volume spread, the fire spread in Class II commodity appears better represented as two-dimensional (no variation with height) surface spread into the crossing radial flue spaces. Defining a heat release rate per unit surface area of combustible material (corrugated layer over steel box), $Q_{s}^{\prime \prime}$, the total heat release rate is, approximately: 
where $D_{s}$ is twice the radial spread of pyrolyzing surface in the radial flues and $h_{s}$ is the height of the storage. A constant value for $Q_{s}^{\prime \prime}$ was assumed, evaluated using Eq. (9) from the heat release rate at the time of full involvement and the full width of the storage $\left(290\right.$ to $\left.320 \mathrm{~kW} / \mathrm{m}^{2}\right)$. From Eq. (10), the fire diameter at any time was then obtained from the associated heat release rate:

$D_{s}=Q /\left(4 Q_{s}^{\prime \prime} h_{s}\right)$

Flame height parameters in terms of the alternative fire diameter, $\mathrm{D}_{\mathrm{s}}$, are plotted as solid circles in Fig. 4. While the alternative dimensionless flame heights still tend to plot above the pool fire reference, the percent deviation from the pool fire curve is considerably smaller than in the original formulation.

The data in Fig. 4 involve flame heights from just above the top of the storage to well above the storage.

\section{Wood Pallets}

All flame height measurements were in the case of the wood pallets based on the plume temperature criterion.

The flame height results are plotted in Fig. 5. The data tend to cluster around the pool fire reference line, except for a tendency to undershoot the reference line at small abscissa values. The cluster of low $\mathrm{L} / \mathrm{D}$ values at small abscissa values are associated with low pallet stacks (2 to 5 pallets) early in the fire. Consequently, they are probably the result of temperature measurements near the center of a split flame from the two ignitors. At more advanced stages of these fires, the flame heights plot close to the pool fire reference line.

\section{VIRTUAL ORIGINS}

The Rack Storage freeburn tests provided detailed cross-stream profiles in the fire plume of temperature rise based on 10-second running averages and the associated convective heat release rate [4], from which maximum, centerline values in the plume could be determined. In many cases, the centerline temperature rise was available at two or more elevations above the flames, allowing the virtual origin to be determined using the technique indicated in conjunction with Eq. (7). The resulting elevations of the virtual origin relative to the base of the fire, $z_{0}$, could then be compared with the value given by the pool fire relation in Eq. (6):

$\mathrm{z}_{\mathrm{o}}=\mathrm{L}-0.175 \mathrm{Q}_{\mathrm{c}}^{2 / 5}$

where $\mathrm{L}$ is now the measured flame height above the fire base. 
The results are plotted as measured $z_{o}$ versus pool fire $z_{o}$ in Fig. 6 . The dashed line is the equality line. Although there is considerable scatter, the data suggest that the pool fire relationship, Eq. (6), is valid. With regard to the scatter, slight inaccuracies in the determination of centerline temperatures have large effects on the intercept, $z_{0}$, using the present technique, i.e., Eq. (7).

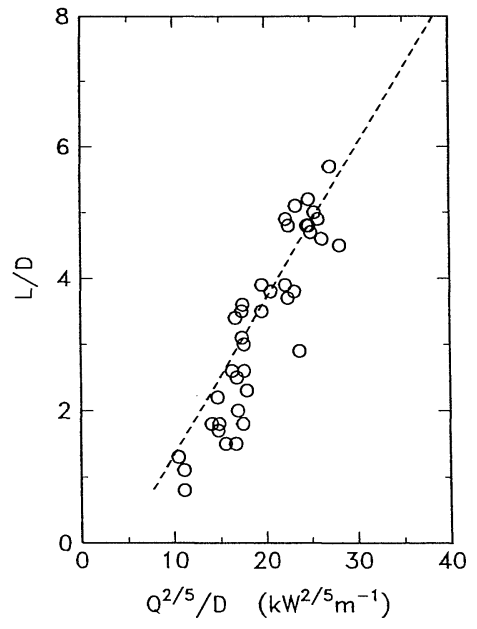

FIGURE 5. Wood Pallet tests: Dimensionless flame heights above base of fire, all based on measurements of plume centerline temperatures. The dashed line is the pool fire correlation in Eq. (4).

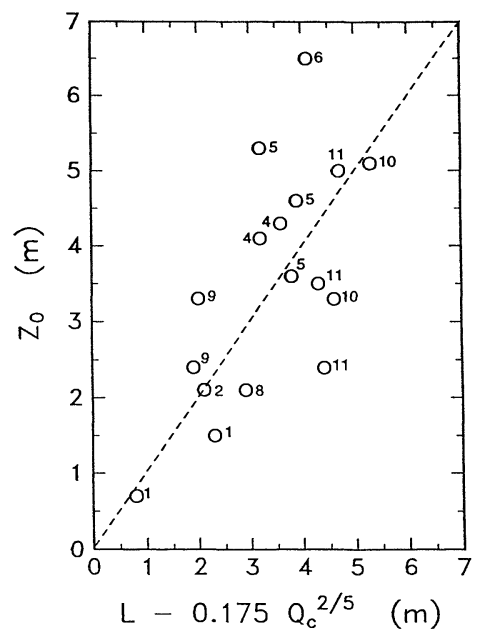

FIGURE 6. Test of the pool fire relation, Eq. (11), for virtual origins, $\mathrm{z}_{\mathrm{o}}$, measured in Rack Storage fires. Dashed line represents Eq. (11).

\section{CONCLUSIONS}

1. The heights of flames extending above the storage of a variety of deep storage fires are reasonably well represented by an often-used correlation for pool fires, Eq. (4), referencing the mean flame height to the base of the combustion region and representing the fire diameter as $\mathrm{D}=\left[4 \mathrm{Q} /\left(\pi \mathrm{Q}^{\prime \prime}\right)\right]^{1 / 2}$ as if the fire spreads as a cylindrical volume in the storage. An exception was a series of rack storage fires of a commodity comprising pallet loads of a relatively thin, combustible layer of corrugated carton over an inert, steel box (FMRC Class II commodity); however, flame heights from these tests also conformed when the fire diameter was represented in a manner consistent with surface spread rather than volume spread.

2. Mean flame heights based on visual averaging are consistent with heights based on a characteristic mean temperature rise $\left(500^{\circ} \mathrm{K}\right)$ in the manner observed for pool fires.

3. Virtual origins derivable for the rack storage fires appear predictable from the flame height as in pool fires; Eq. (11) is a useful form when convective fractions of the total heat release rate are much smaller than in pool fires. The prediction of virtual origin requires both the convective heat release rate (Eq. [11]) and the total heat release rate (Eq. [4]). 


\section{REFERENCES}

1. Heskestad, G., "Fire Plumes," in SFPE Handbook of Fire Protection Engineering (P.J. DiNenno, Ed.), Second Edition, NFPA and SFPE, 1995, pp. 2-9 - 2-19.

2. Dean, R.K., "Stored Plastics Test Program," FMRC Ser. No. 20269, Factory Mutual Research Corporation, Norwood, MA, June 1975.

3. Krasner, L.M., "Burning Characteristics of Wooden Pallets as a Test Fuel," Ser. No. 16437, Factory Mutual Engineering Association, Norwood, MA, May 1968.

4. Yu, H-Z and Kung, H-C, "Strong Buoyant Plumes of Growing Rack Storage Fires," FMRC J.I. 0G2E7.RA(1), Factory Mutual Research Corporation, Norwood, MA, February 1984.

5. Yu, H-Z and Kung, H-C, "Strong Buoyant Plumes of Growing Rack Storage Fires," Twentieth Symposium (International) on Combustion, The Combustion Institute, Pittsburgh, PA, 1984, pp. 1547-1554.

6. Heskestad, G., "Peak Gas Velocities and Flame Heights of Buoyancy-Controlled Turbulent Diffusion Flames," Eighteenth Symposium (International) on Combustion, The Combustion Institute, Pittsburgh, PA, 1981, pp. 951-960.

7. Ricou, F.P. and Spalding, D.B., "Measurements of Entrainment by Axisymmetrical Turbulent Jets," J. Fluid Mechanics, Vol. 11 (1961), pp. 21-32.

8. Heskestad, G., "Luminous Heights of Turbulent Diffusion Flames," Fire Safety Journal, Vol. 5 (1983), pp. 103-108.

9. Heskestad, G., "A Reduced-Scale Mass Fire Experiment," Combustion and Flame, Vol. 83 (1991), pp. 293-301.

10. Heskestad, G., "Virtual Origins of Fire Plumes," Fire Safety Journal, Vol 5 (1983), pp. 109-114.

11. "Stored Plastics Test Program," Project File, FMRC Ser. No. 20269, FMRC Library, Factory Mutual Research Corporation, Norwood, MA.

12. Tewarson, A., "Generation of Heat and Chemical Compounds in Fires," in SFPE Handbook of Fire Protection Engineering (P.J. DiNenno, Ed.), Second Edition, NFPA and SFPE, 1995, pp. 3-53 - 3-124. 